ЛАПШИН Аркадий Олегович - кандидат исторических наук, главный редактор журнала «Власть», член президиума Академии политической науки (117218, Россия, г. Москва, ул. Кржсикановского, d. 24/35, кopn. 5; ark2050@yandex.ru)

\title{
К ОСМЫСЛЕНИЮ ИСТОРИИ ВЧЕРА И СЕГОДНЯ
}

\begin{abstract}
Аннотация. В статье главного редактора журнала «Власть» поднимаются актуальные вопросы деформации исторического нарратива в современном политическом и научном дискурсе, что вылилось в настоящие войны памяти, особенно вокруг фальсификации фундаментальных вопросов Второй мировой войны. Требуется серьезный ответ, основанный на безусловных, объективных фактах и документах. Автор настаивает на использовании богатейшего наследия отечественных историков для сохранения исторической памяти, считая это задачей не только научной, но и политической. В этой связи своевременна монография Ю.А. Васильева «Теория и методы в русской исторической школе: Теория исторического знания, теория исторического процесса, психологическое направление», в которой представлены теоретические основания русской исторической школы. Сегодня необходимо использовать идеи и концепции отечественных историологов, чтобы преодолеть интеллектуальную инерцию и обеспечить подлинно научную реконструкцию прошлого.
\end{abstract}

Ключевые слова: историческое знание, войны памяти, фальсификация истории, историология, психологическое направление, методы, русская историческая школа.

$\mathrm{B}$ течение последних двух лет на страницах журнала «Власть» продолжается дискуссия о феномене исторического, истории, исторической науки и, говоря шире, об особенностях гуманитарного знания, специфике реконструкции прошлого [Черняховский 2017; Асонов 2018; Бельков 2018; Васильев 2019]. Своеобразие государственного устройства современной России, равно как и модель будущего российского общества, органически связано с прошлым. «Новое в старом» - формула, выражающая преемственность исторического процесса. Сегодняшнее время и прошлое соединены в культуре, традициях, ценностях живущих сейчас поколений.

В периоды юбилейных дат, этапных событий, пороговых трансформаций общества или мир-системы всегда обостряется борьба за интерпретацию исторического прошлого. «Устои привычного и кажущегося незыблемым мира рушатся, и на повестку дня встают последние экзистенциальные вопросы, писал выдающийся русский культуролог Андрей Пелипенко, - мысль вновь обращается к идее предопределенности настоящего и будущего историческим прошлым» [Пелипенко 2017: 8]. Весьма примечательно, что в подстрочнике автор обращает внимание на то, что исторический релятивизм в такого рода практиках дает всегда «нужный» результат. «Такое упрощенно-поверхностное понимание исторического бытия присуще, что характерно, главным образом технократическому мышлению» [Пелипенко 2017: 8]. Именно данный тип мышления не только ведет к депрофессионализации знания вообще и гуманитарного знания в частности, но реально влияет на практическую политику.

Сегодня в истории Второй мировой войны мы видим резкое обострение трактовок причин и ответственности за развязывание войны. Ответственность за эрозию исторического нарратива несут страны Запада, в первую очередь бывшей Восточной Европы. Для российского массового и научного сознания тема Великой Отечественной войны является глубоко экзистенциальной. Слишком дорого заплатил наш народ за победу над фашизмом. И здесь историческое знание, основанное на документальных фактах и научной реконструкции прошлого, играет исключительно важную роль. Любые попытки фальсификации 
истории, основанные на сегодняшних политических клише и осуществляющиеся в интересах отдельных групп, ведут к конфликтам на личностном и межгосударственном уровнях. «Увы, воссоздавать прошлое по лекалам порожденных им мифов всегда проще», - пишет известный российский историк Владимир Булдаков [Булдаков 2012: 9].

Вообще предрассудки и утопии в реконструкции исторического прошлого возникают не случайно. Они являются попытками определенных кругов (политических и научных, которые сегодня служат политическим кругам) решать посредством фальсификации исторических фактов сегодняшние задачи. Это «нарративное наступление», т.е. стремление радикально переформатировать прежнее историческое повествование о войне, ее причинах и последствиях, имеет и внешнеполитические, и внутриполитические задачи», - говорит руководитель Центра изучения культурной памяти и символической политики Европейского университета в Санкт-Петербурге Алексей Миллер [Миллер 2020]. В условиях глобализации такие попытки приобретают массовый характер. Они не только деформируют историческое прошлое, но и формируют симулятивную реальность в настоящем. Именно поэтому столь важно для нас, особенно в год 75-летия Победы, постараться одержать еще одну победу - в войне вокруг исторической памяти.

Хочу особо отметить, что хроноцентризм в изображении прошлого - органическая слабость и массового, и научного сознания. Мы невольно переносим наши сегодняшние оценки и смыслы на вчерашние и позавчерашние события. Так проще объяснить моменты социально-психологической преемственности, идентичности, наконец, архетипичности. Но когда в «прошлое» пытаются вбросить сегодняшнюю матрицу русофобии и объявляют это действо исторической правдой, тогда требуется серьезный ответ, основанный на безусловных, объективных фактах и документах. Именно об этом говорил недавно президент В.В. Путин.

В этой связи очень своевременно в издательской группе URSS вышла в свет книга доктора исторических наук профессора Ю.А. Васильева [Васильев 2020]. В ней представлено авторское осмысление становления отечественных традиций в историописании, в первую очередь синтетических построений выдающихся теоретиков русской исторической школы второй половины XIX - начала XX в. Работа выполнена в исследовательской традиции «философствующего историка». Именно таким, по мысли выдающегося российского историка и социолога XIX-XX вв. Н.И. Кареева, должен быть настоящий, квалифицированный специалист в исторической науке. Основы данной традиции, предполагающей разработку истории, в которой исследователь оперирует определенными идеями, теориями, основанными на достоверных фактических данных, были определены еще в первой половине XIX в. историками гейдельбергской школы в Германии (Г.Г. Гервинус).

Автор обосновывает утверждение, что развитие теоретических и методологических основ русской исторической школы происходило соразмерно эволюции интеллектуальной мысли в Западной Европе. В понимании многих проблем в теории истории российские ученые опередили западных современников [Васильев, Васильева 2014]. Достижения русской исторической школы в области теории исторического знания, теории исторического процесса, в разработке психологического направления находились в русле европейской историографии, и сегодня они в мейнстриме современных идей мировой исторической науки. Парадигмальная близость российских и западноевропейских мыслительных практик свидетельствует о единой социокультурной основе народов России и Европы. 
В частности, в истории русской науки существует малоизвестный сегодня даже для специалистов факт признания западными учеными Ecole russe (русской школы). Данный термин, введенный в оборот в последней четверти XIX в. Ж. Жоресом, до сих пор имеет широкое хождение у французских историков. Под знаменитой в Европе Ecole russe имеются в виду прежде всего трое выдающихся русских ученых - Н.И. Кареев, М.М. Ковалевский и И.В. Лучицкий. Ecole russe является выдающимся феноменом русской исторической науки не только по причине ее международного признания: данный феномен сам по себе был обращен не столько к накопленному историческому опыту, сколько к тому историческому знанию, которое предстояло освоить в будущем.

Теория истории, созданная Н.И. Кареевым, представляет собой синтетическую систему как в структурном плане, так и в содержательном [Васильев 2011б; 2012a; 2012б; 2019; 2020: 29-121]. Ее по праву можно рассматривать как достижение не только русской исторической школы, но и всей мировой интеллектуальной мысли. Эта теория актуальна не только для периода расцвета школы на рубеже $\mathrm{XIX}-\mathrm{XX}$ вв., но и для сегодняшнего дня. В трудах французской школы «Анналов» (М. Блок, Л. Февр, Ф. Бродель и др.) в XX в. исследования велись в рамках синтеза социологии, обществоведения и истории. Воплощение Кареевым в личности универсально-творческого начала истории имеет параллель с универсально-исторической социологией Норберта Элиаса (личностное начало истории как основной принцип). По оценке автора книги, теория истории Кареева, основанная на использовании психологических аспектов в понимании историологии, позволяет утверждать, что именно Н.И. Карееву принадлежит право называться основоположником психологического направления в русской исторической школе. Концептуальные идеи Кареева позволили ему оформить психолого-историческое направление в системное теоретическое знание.

Адепты современного радикального либерализма в попытках переписать историю зачеркивают не только научный подход - их цель искусственными мифологемами создать иную реальность. Разрушая историческую память, они разрушают настоящее, подрывая тем самым будущее. И здесь для содержательного научного дискурса обращение к видным гуманитариям недавнего прошлого исключительно полезно.

По мнению Ю.А. Васильева, основные положения теории истории, сформулированные В.О. Ключевским, позволяют считать его, наряду с Кареевым, основоположником психологического, а также нового, «социологического» направления в исторической науке [Васильев 2020: 122-219; Васильев 2011а].

Теория истории А.С. Лаппо-Данилевского в значительной степени продвинула неокантианство В. Виндельбанда и Г. Риккерта. Его размышления ассоциативны с феноменологическим направлением, в частности с феноменологией Э. Гуссерля, и созвучны с философией жизни В. Дильтея, Г. Зиммеля (признание принципа чужой одушевленности, понимание «чужого» сознания, «чужого Я»), современной теорией возвышенного исторического опыта Ф. Анкерсмита. Наряду с Н.И. Кареевым, В.О. Ключевским, А.С. Лаппо-Данилевский в полной мере может быть назван одним из основателей психологического направления в русской исторической школе. Он также стоял у истоков исторической аксиологии, которая занимается проблематикой ценностей (фактов, явлений, личностей) [Васильев 2020: 220-261].

Интерпретация истории, характерная для исследований представителей русской исторической школы, значительно позднее нашла отражение в работах их западноевропейских последователей, например представителей знаменитой французской исторической школы «Анналов», сложившейся в 30-40-х гг. XX в. 
Обращение к человеку и его деятельности как важному предмету исторической науки, характерное для разных поколений школы «Анналов» в XX в., начиная с ее основателей (М. Блок, Л. Февр), разрабатывалось в последние десятилетия XIX в. в синтетических построениях Н.И. Кареева о личности и обществе в истории, о феномене «великих людей» в истории; в концептуальных положениях В.О. Ключевского о человеческой личности и «людском обществе» как исторических силах, о человеческом общежитии; в обращении к человеческой психике и феномену «другого», принципе признания чужой одушевленности, «чужого Я», единства человеческого сознания у А.С. Лаппо-Данилевского, в конструктах многих других выдающихся теоретиков русской исторической школы или ее отдельных значимых частиц (таких, как Ecole russe).

Общественное сознание, которое представители школы «Анналов» изучали как ментальности, уже было известно под названием «общественная психология». Интерес к вопросам общественной психологии в объяснении исторического процесса был проявлен прежде С.М. Соловьевым в размышлениях о «природе племени», затем продолжен В.О. Ключевским в русле концептов исторических сил, исторических элементов, народно-психологического (по его терминологии) обоснования крупных исторических явлений (таких, как церковный раскол). Если «анналисты» не допускали в предмет исследования мотивы поведения людей, то в теории истории Ключевского в качестве важных факторов исторического развития рассматривались мотивационные особенности людей, социальных групп, общества, что нашло отражение, в частности, в блестящих социально-психологических характеристиках ключевых фигур русской истории. Русский ученый установил взаимосвязь исторического мышления и конкретных исторических условий и особенностей общественного развития и их зависимость друг от друга. Нельзя не вспомнить также крупного русского психиатра академика В.М. Бехтерева с его теорией коллективной рефлексологии. Он является одним из основателей такой науки, как социальная психология, и автором закона, который он назвал законом исторической последовательности, использовав его для оценки двух наших революций: Февральской и Октябрьской [Бехтерев 1921: 356].

Примечательно следующее обстоятельство: французских «анналистов» в XX в., как и теоретиков русской исторической школы в XIX в., подвергали критике за «теоретический эклектизм». Однако данный упрек означает лишь непонимание синтетических замыслов мыслителей. Именно в их историческую эпоху наступила пора систем как органического связывания накопленного материала. Поэтому появилась задача органического синтеза всего, что было высказано прежде, в отдельных построениях, причем синтеза в виде системы. Такое системное понимание исторического процесса - важнейшая составляющая всего современного гуманитарного знания. Спекулятивный технократизм, замешанный на сиюминутной политической конъюнктуре, не имеет ничего общего с серьезным теоретико-культурологическим дискурсом.

В современном синтетическом построении истории происходит расширение терминологического словаря, соответствующего нынешнему уровню исторического знания. Кроме словаря описания и объяснения, а также словаря смысла и интерпретации, общий тезаурус историографии пополнил словарь исторической репрезентации. Историк репрезентирует историческую реальность, придавая ей смысл через смысл своего текста, т.к. реальность сама по себе этого не имеет. «При этом действует древнейший психологический механизм: если нечто убирается из семантического поля, то тем самым оно как бы убирается и из самой реальности», - писал Андрей Пелипенко [Пелипенко 2014: 211]. 
Можно утверждать, что построения русских теоретиков истории создали основу теории и методологии истории, которая стала источником последующих заимствований в зарубежной науке. Отражение идей русских мыслителей обнаруживается в появлении в западной теоретической мысли XX в. различных исторических направлений: концептуальной истории, интеллектуальной истории, экономической истории, политической истории, социокультурной истории, культурно-социальной истории, глобальной истории, биографической истории и др., а также многочисленных их трансформаций с термином «новая».

Вообще специфика гуманитарного знания требует своего дальнейшего осмысления. Гуманитарные науки (от humanus - человеческий) специализируются на человеке и его жизнедеятельности в обществе. Они включают в себя дисциплины, изучающие человека в духовной, умственной, нравственной, культурной сферах, в общественной деятельности. По объекту, предмету и методологии изучения они пересекаются (и отождествляются) с общественными науками, противопоставляются при этом точным наукам. Ставить на одну доску техническую науку с ее узко утилитаристским подходом и гуманитарные дисциплины - непростительная роскошь, которая заканчивается потерей эвристических характеристик и у гуманитарного знания, и у академической науки вообще. Технознание эффективно в тех сферах человеческой деятельности, которые легко алгоритмизируются, обслуживая современное массовое производство.

Природа гуманитарного знания, его базовые составляющие, мягко говоря, не похожи на некоторые особенности точных, естественных наук. Так, в квантовой физике не может быть «единой правды». Измерения с разных позиций (по признанию самих физиков) дадут различные результаты и будут одинаково верны. Перенос данной парадигмы в гуманитарное знание приводит к релятивизму, хаосу смыслов и фактически - к фальсификации исторического прошлого. Тем самым история как наука превращается в инструмент идеологии и конъюнктурной политики.

В гуманитарном знании можно выделить две составляющие: условное и безусловное знание, причем это относится, прежде всего, к исторической науке. Условное знание видоизменяется, его содержание более подвижно. Чем дальше от нас находится историческое явление или процесс, тем больше его теоретическое осмысление освобождается от идеологических или мифологических напластований. Это нормальный процесс эволюции любого гуманитарного знания, в т.ч. и исторического.

Безусловное историческое знание требует особо корректного к себе отношения и со стороны научного сообщества, и со стороны политиков. Но, как правило, именно оно попадает под каток различных идеологических и мифологических штампов и фобий. Фундаментальные выводы Нюрнбергского процесса являются безусловными и абсолютными итогами Второй мировой войны, если хотите, безусловными историческими фактами. Любые попытки переписать их не просто недопустимы с точки зрения исторической правды. Такие шаги разрушают саму глубинную природу социокультурных основ цивилизации. К сожалению, это происходит...

В заключение хотелось бы сказать, что использование богатейшего наследия отечественных историков для сохранения исторической памяти - задача не только научная, но и политическая. В условиях глобализации, когда стираются социокультурные особенности и идентичности, реконструкция прошлого превращается в острейшее научное и информационно-идеологическое противостояние, в войны памяти. Тем не менее в настоящее время все отчетливее фиксируется тренд на идентичность - культурную, социальную, гражданскую, 
этническую и конфессиональную. При этом, естественно, меняются параметры государственного управления и стратегического планирования, протекающие в условиях цифровой революции. Устойчивость и экологичность в трансформациях индивидуальной и коллективной жизни приобретают не просто желательный характер, они становятся условиями дальнейшего прогресса. И здесь цифровизация уже играет свою роль в поиске модели оптимизации дальнейшего развития, снятия части вызовов и рисков. Одновременное сосуществование двух фундаментальных векторов развития - глобализации и идентичности - создают неповторимую картину сегодняшнего времени. История делает очередной виток в своем движении. О каком конце истории можно сегодня говорить? Скорее наоборот, мы видим в условиях цифровой революции новый разворот движения социума и одновременно новые вызовы и риски, которые здесь возникают. Благодатное время для гуманитарного знания, но не нужно его превращать в придаток технонауки, обслуживающей прикладные сферы человеческой деятельности.

В этой связи сохранение исторической памяти является условием дальнейшего развития российского общества - оно обеспечивает преемственность поколений и лежит в основе культурного кода народа. Российская общность - сложное системное образование. Оно имеет гражданскую, политическую, полиэтническую и поликонфессиональную идентичности. Вероятно, под влиянием глобализации можно добавить сетевые, цифровые коммуникативные характеристики общероссийской идентичности. Но и под оболочкой цифры скрывается живая память поколений.

Обновление аналитического дискурса по фундаментальным проблемам российского общества, особенно таких его драматических событий, как революции или войны, должно оставаться в русле фундаментальных критериев исторического знания. Его величество исторический факт не должен приноситься в жертву сиюминутным и подчас конъюнктурным интересам, не говоря уже о русофобских или каких-то иных клише. Безусловно, историческая наука имеет свою особую природу, но ее нельзя запирать в русле релятивизма и кампанейщины. Только таким путем удастся преодолеть интеллектуальную инерцию и обеспечить подлинно научную реконструкцию прошлого.

Книга профессора Ю.А. Васильева аккумулирует бесценный исторический опыт российских историков, показывая его связь с европейскими интеллектуальными традициями. Отечественное историописание недавнего прошлого, особенно некоторые фрагменты его методологии, и сейчас могут сыграть свою роль и войти в инструментарий современных ученых. Вспомним в заключение замечательную мысль нашего выдающегося историка Н.М. Карамзина: «История - не роман, и мир не сад, где все должно быть приятно: она изображает действительный мир».

\section{Список литературы}

Асонов Н.В. 2018. История как наука. - Власть. Т. 26. № 2. С. 45-48.

Бельков О.А. 2018. История: наука или идеология? - Власть. Т. 26. № 7. С. 76-82.

Бехтерев В.М. 1921. Коллективная рефлексология. Петроград: Колос. 432 с.

Булдаков В. 2012. Утопия, агрессия, власть: Психосоциальная динамика постреволюционного времени. Россия, 1920-1930 г2. М.: РОССПЭН. 756 с.

Васильев Ю.А. 2011а. Идентичность русского народа в исторической концепции В.О. Ключевского. - Власть. № 7. С. 35-39.

Васильев Ю.А. 2011б. Феномен «Ecole Russe»: критика Н.И. Кареева. - Знание. Понимание. Умение. № 3. С. 121-127. 
Васильев Ю.А. 2012а. Взгляд на эпометаморфоз сквозь призму всемирноисторической точки зрения. - Век глобализации. № 1. С. 46-57.

Васильев Ю.А. 2012б. Феномен «Еcole russe»: историология Н.И. Кареева. Знание. Понимание. Умение. № 1. С. 72-81.

Васильев Ю.А. 2019. Нужна ли единая парадигма в исторической эпистемологии. - Власть. Т. 27. № 2. С. 199-205.

Васильев Ю.А. 2020. Теория и методы в русской исторической школе: Теория исторического знания, теория исторического процесса, психологическое направление. Изд. стереотип. М.: КД «ЛИБРОКОМ». 272 с.

Васильев Ю.А., Васильева, М.Ю. 2014. Влияние идей Христиана Вольфа на мировоззрение М.В. Ломоносова. - Власть. № 3. С. 121-125.

Миллер А. Почему Россия больше не может игнорировать войны памяти. - Профиль. 03.02.20. Доступ: https://profile.ru/politics/sboj-pamyati-kak-rossiyuvtyanuli-v-novye-istoricheskie-vojny-v-evrope-220129/ (проверено 27.02.2020).

Пелипенко А.А. 2014. Глобальный кризис и судьбы Запада. М.: Знание. 224 с.

Пелипенко А.А. 2017. Постижение культуры: в 2 ч. Ч. 2. Мифоритуальная система. Кн. 1. Медиационная парадигма. М.: РОССПЭН. 504 с.

Черняховский С.Ф. 2017. О целях и задачах исторического исследования. Bласть. Т. 25. № 12. С. 7-10.

\title{
ON COMPREHENDING THE HISTORY YESTERDAY AND TODAY
}

\begin{abstract}
The article by the editor-in-chief of the Vlast' journal raises topical issues of the deformation of historical narrative in contemporary political and scientific discourse, which resulted in real memory wars, especially around falsification of fundamental issues of the World War II. A serious answer is required based on unconditional, objective facts and documents. The author insists on using the rich heritage of domestic historians to preserve historical memory, considering this a task not only scientific, but also political one. In this regard, the monograph by Yu.A. Vasil'ev «Theory and Methods in the Russian Historical School: Theory of Historical Knowledge, Theory of the Historical Process, Psychological Direction", which presents the theoretical foundations of the Russian historical school is well-timed. Today it is necessary to use the ideas and concepts of Russian historians to overcome intellectual inertia and ensure a truly scientific reconstruction of the past.
\end{abstract}

Keywords: historical knowledge, memory wars, falsification of history, historiology, psychological direction, methods, Russian historical school 